\title{
Selected Fatty Acids Esters as Potential PHB-V Bioplasticizers: Effect on Mechanical Properties of the Polymer
}

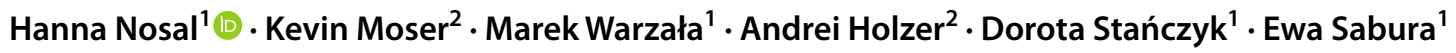

Published online: 13 August 2020

(c) The Author(s) 2020

\begin{abstract}
Poly(3-hydroxybutyrate-co-3-hydroxyvalerate) (PHB-V) has not been used for demanding technical applications yet due to its limited mechanical properties, particularly its high brittleness. An appropriate route to overcome these limitations is the implementation of plasticizers in the PHB-V matrix via compounding. In this paper the use of different types of fatty acids esters as PHB-V plasticizers were investigated. The study describes how the difference in the fatty acid esters structure (mainly fatty acid hydrocarbon chain length) affects their plasticizing effect and thus the PHB-V ductility performance. The best impact properties of PHB-V compounds were obtained for oleic acid methyl ester, palmitic acid methyl ester or lauric acid ethylene glycol monoester. The increase of notched impact strength from 1.4 (for neat polymer) to $4.0-4.1 \mathrm{~kJ} / \mathrm{m}^{2}$ was observed. At the same time stiffness and strength of the polymer decreased but remain on a level sufficient for technical applications. Additional drawback of PHB-V materials is increasing the brittleness over time. Moreover this study shows that the use of oleic acid ethylene glycol monoester or stearic acid ethylene glycol monoester as plasticizers significantly reduces the increase of the brittleness of PHB-V over time. It is relevant that this drawback of PHB-V materials can be significantly improved by plasticizer addition.
\end{abstract}

Keywords PHB-V $\cdot$ Fatty acids esters $\cdot$ Bio-based plasticizer $\cdot$ Mechanical properties

\section{Introduction}

Hanna Nosal

nosal.h@icso.lukasiewicz.gov.pl

Kevin Moser

kevin.moser@ict.fraunhofer.de

Marek Warzała

warzala.m@icso.lukasiewicz.gov.pl

Andrei Holzer

andrei.holzer@ict.fraunhofer.de

Dorota Stańczyk

stanczyk.d@icso.lukasiewicz.gov.pl

Ewa Sabura

sabura.e@icso.lukasiewicz.gov.pl

1 Renewable Raw-Materials Department, ŁUKASIEWICZ Research Network - Institute of Heavy Organic Synthesis "Blachownia", Energetyków 9, 47-225 Kędzierzyn-Koźle, Poland

2 Fraunhofer Institute for Chemical Technology ICT, Joseph-von-Fraunhofer-Straße 7, 76327 Pfinztal, Germany
In recent years various reports have shown processing routes for the lab-scale biosynthesis of polyhydroxyalkanoates (PHAs) using different carbon sources and strains of bacteria $[1,2]$. PHAs manufactured via microbial route are classified a fully biodegradable family of polymers that in terms of performance are quite similar to polypropylene. PHB poly(3-hydroxybutyrate) and its copolymers, e.g. poly(3hydroxybutyrate-co-3-hydroxyvalerate) PHB-V, are the most popular members of the PHAs. Both -PHB and PHB-V as a thermoplastic polymer- can be processed using conventional equipment [3,4]. Potentially, these polymers could be used for the production of films, fibres, packaging materials or thermoformed rigid products. However PHAs are more rigid and less flexible than e.g. polypropylene, due to their higher crystallinity [5]. PHB is a stiff and brittle polymer and additionally it is characterised by a poor thermal stability and a narrow range of processing temperature. This results in weak mechanical properties with low elongation at break properties. 
One of the methods to reduce the brittleness and improve the mechanical properties of PHB is synthesis of copolyesters containing 3-hydroxybutyrate units and other units like 3-hydroxyvalerate (PHB-V) [6]. PHB-V is a less stiff and less brittle material than the pure PHB [7], but still not sufficient for demanding technical applications. Consequently, the utilization of PHAs substituting synthetic polymers remains a challenge. Depending on the specific application PHAs require modifications to achieve a better performance, particularly optimized mechanical properties and a sufficient stability with respect to the designated end-of life scenario. This means in case of short term applications such as single use plastics a fast biodegradability and in case of long-term use a sufficient stability to enable mechanical recycling and subsequently the re-use the polymer in new products [8-10].

A simple and inexpensive method for improving some mechanical properties of polymers is their blending with additives. In order to overcome the mechanical drawbacks in some PHB and PHB-V properties, various types of additives have been tested, mainly fillers [11], nucleating agents [12] and plasticisers [13]. The addition of plasticizers should improve the polymer mechanical performance (ductility, elongation at break) and its processability (lowering glass transition temperature and allowing the processing at lower temperature). To gain all these results the plasticizer should be compatible with the polymer system.

Several scientific studies report the potential to improve the mechanical and thermal PHB properties by adding petrochemical based plasticizers by adding petrochemical based plasticizers e.g. dioctyl adipate, dioctyl phthalate, dibuthyl phalate, polyadipate, poly[di(ethylene glycol)], tri(ethylene glycol), bis(2-ethylhexanoate) [3,13-15] but also selected bio-based plasticizers. In this paper we would like to focus on bio-based plasticizers dedicated for PHA. Plasticizers of petrochemical origin will be mentioned as reference material.

Bio plasticizers with very low molecular mass like glycerol and glycerol triacetate were tested by Janigova et al. [16]. In this work, unlike in most cases, the focus was not on the effectiveness of these compounds as plasticizers but on the impact of the used plasticizers on thermal degradation of PHB. It appeared that the PHB degradation is substantially accelerated with the use glycerol as plasticizer while glycerol triacetate (triacetin) is inert in this aspect. Probably it is caused by glycerol ability to enter the alcoholysis reaction with polymer carboxyl end groups. Glycerol esters as PHB plasticizers were also used by Abe et al. [17]. In this study however beside glycerol triacetate, glycerol monostearate and glycerol tristearate were used. Another interesting group of biobased plasticizers are citric acid derivatives. This type of compound, specifically acetyl tributyl citrate, was used by Erceg et al. [18] as a PHB modifier. The addition of acetyl tributyl citrate leads to the melting temperature decrease and minimal positive effect on PHB crystallinity. The same plasticizer was also used by Branciforti et al. [19] for PHB-V and organo-modified montmorillonite composite. Plasticized composites have higher impact absorption capacity than composite without plasticizer addition but lower modulus of elasticity and yield strength.

Baltieri et al. [3] tested plasticization of PHAs with the use of triacetyl glycerol, dioctyl adipate and polyadipate. The best results were obtained when $30 \mathrm{wt} \%$ of triacetyl glycerol or composition $20 \mathrm{wt} \%$ polyadipate and $10 \mathrm{wt} \%$ triacetyl glycerol were used as plasticizers.

Choi et al. [20] investigated the plasticizers dibutyl phthalate, triethyl citrate, soybean oil and epoxidized soybean oil with an amount of $20 \mathrm{wt} \%$. They concluded that tributyl citrate or dibutyl phthalate perform better than soybean oil and epoxidized soybean oil as PHB-V plasticizers. It can be assumed that fatty acid esters with a branched structure have limited use as PHB-V plasticizers. Requena et al. [7] aimed to improve the mechanical properties of PHB-V films. They incorporated $10 \mathrm{wt} \%$ of polyethylene glycol (PEG 200, 1000 and 4000), lauric acid and stearic acid into the film formulation. All plasticizers, except stearic acid, reduced film stiffness, but among them the most effective at plasticizing PHBV films was PEG 1000 (32\% increment in elongation at break). Yoshie et al. [20] in their work examined effects of low molecular weight additives like dodecanol, lauric acid, tributyrin and trilaurin on PHB properties. All used compounds were miscible with PHB to some particular amounts. According to this research results the miscibility of the additives with polymer is arranged in the following order: tributyrin $(0$ to $23 \mathrm{wt} \%)>$ dodecanol $\approx$ lauric acid $(0$ to $9 \mathrm{wt} \%$ ) > trilaurin ( 0 to $1 \mathrm{wt} \%$ ). The additives molecules differ significantly in chemical structure. It can be seen that the small branched tributyrin molecule miscible with PHB is much better than the analogous structure of trilaurin, however, containing much longer hydrocarbon chains. Tributyrin, dodecanol, lauric acid and trilaurin improved the mobility of the PHB molecules in the amorphous phase and acted as plasticizers. Interestingly, the addition of these compounds also affects enzymatic degradation of the PHB chains. Their small amount (1 wt $\%)$ act as accelerator of this process.

Low-molecular compounds e.g. dioctyl sebacate, dibutyl sebacate, polyethylene glycol, and Laprol 503 (oligoether) were also tested as PHB plasticizers by Bibers et al. [21]. Up to a content of 15-20 wt\% all of them are compatible with the PHB and form with this polymer a single-phase system. Increasing the content of plasticizer causes increase the relative breaking elongation of PHB but also it results in decrease the strength of the system. It means that this plasticizers content should not exceed $20 \mathrm{wt} \%$. Savenkova et al. [22] tested as PHB plasticizers compounds with similar structure. The following compounds were used: 
dibutylsebacate, dioctylsebacate, oxypropylated glycerol of molecular mass 5000 (laprol) and polyethylene glycol of molecular mass 300. Increased PHB flexibility was observed from a plasticizer content of $15 \% \mathrm{w} / \mathrm{w}$, with the best result obtained for oxypropylated glycerol. Unfortunately this plasticizer retarded biodegradation of the PHB.

Comparisons of the effect of plasticizers differing in molecular weight on the PHB-V mechanical properties were also carried out. In these studies propylene glycol, glycerol, triethyl citrate, castor oil, epoxidized soybean oil and polyethylene glycol were applied [23]. Propylene glycol, castor oil and epoxidized soybean oil did not increase significantly elongation at break while, glycerol, triethyl citrate, and polyethylene glycol did. However only triethyl citrate resulted in a continuous increase in elongation at break with an increasing concentration. The results lead to the conclusion, that medium molecular weight substances with oxygen-containing polar functional groups accessible for interactions with PHB-V like triethyl citrate are the most suitable plasticizer among those surveyed. Ethylene glycol or glycerol namely low molecular weight compounds with hydroxyl groups do not lead to a significant plasticizing effect in PHB-V. According to the authors, the reason for this is most likely a saturation of PHBV at small concentrations. Triglycerides, like castor oil or epoxidized soybean oil also do not lead to significant improvements of the PHB-V flexibility. In their case the long side chains might hinder an interaction of the carbonyl or hydroxyl group with the PHB-V. Based on the results of Jost et al. [24] it can be assumed that the highly branched structure compounds with high molecular weight are not effective as plasticisers.

The chemical structure of the plasticizer, its molecular weight as well as content of functional groups and chemical composition affect their plasticization properties. In our opinion, the modification of biopolymers like PHB should be carried out using biobased additives. In this paper, the influence of seven biodegradable fatty acid based plasticizers on mechanical properties of PHB-V was analyzed. Each plasticizer is characterised by linear structure and contains polar groups with oxygen atoms accessible for interactions with PHB-V in their structure (Fig. 1). The first three of them are fatty acid methyl esters (FAME) differing in the type of fatty acid. The subsequent four plasticizers are ethylene glycol monoesters also differing in the type of fatty acid. The difference in fatty acids applies to fatty acid length and its saturation. At first, the compatibility of synthesized plasticizers with PHB-V was examined and then the PHB-V plasticization effectiveness was evaluated by mechanical characterization. As a result, the present study will make an essential contribution to overcome the specific disadvantages

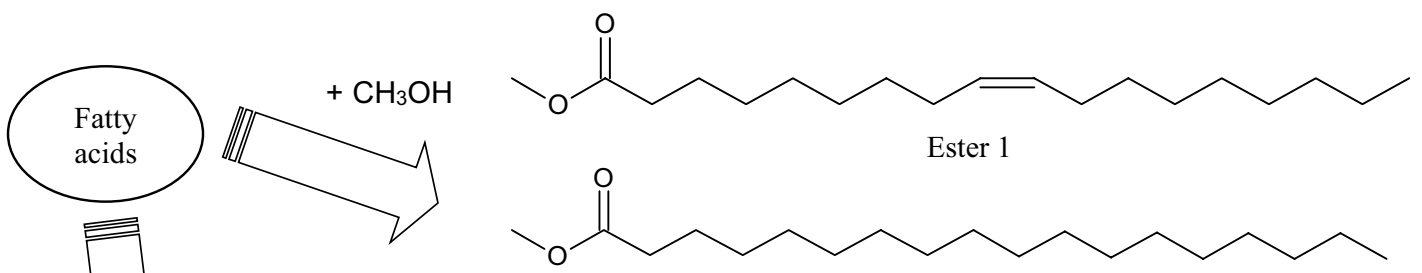

Ester 2

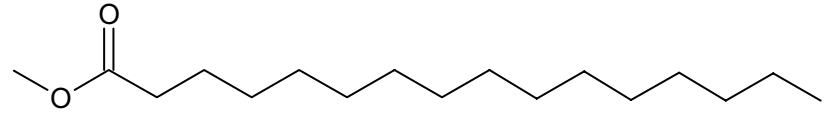

Ester 3<smiles>CCCCCCCC/C=C/CCCCCCCC(=O)OCCO</smiles>

Ester 4<smiles>CCCCCCCCCCCCCCCCCC(=O)OCCO</smiles>

Ester 5<smiles>CCCCCCCCCCCCCCCC(=O)OCCO</smiles>

Ester 6<smiles>CCCCCCCCCCCC(=O)OCCO</smiles>

Ester 7

Fig. 1 The chemical structures of the proposed fatty acid—based PHB-V plasticizers 
of PHB-V and provide further arguments for the use of this biopolymer in technically demanding applications.

\section{Materials and Methods}

\section{Materials}

\section{Ester Synthesis}

A commercial technical grade of oleic acid (purity: 90.0\%) (Alfa Aesar), stearic acid 90\% (Alfa Aesar), palmitic acid 98.0\% (Alfa Aesar), lauric acid $>98.0 \%$ (TCI), methanol pure p.a. (POCH, Poland), ethylene glycol (POCH, Poland), methanesulfonic acid $>99.0 \%$ (TCI), toluene pure p.a. (Chempur, Poland), cyclohexane 99.5\% (POCH, Poland), glycerol 99.5\% (Brenntag, Poland), potassium hydroxide pure p.a. (POCH, Poland), potassium hydrogen carbonate pure p.a. (POCH, Poland) and potassium chloride pure p.a. (POCH, Poland) were used in this study to synthesize particular esters. All raw materials were used without any further purification.

\section{Polymer}

As polymer PHB-V [poly(3-hydroxybutyrate-co-3-hydroxyvalerate)] was used. The highly crystalline PHB-V grade Enmat $^{\mathrm{TM}}$ Y 1000P was supplied by Tianan Biologic Materials (China). In molten stage it shows odourless to slightly sourish odour, specific gravity of $1.25 \mathrm{~g} / \mathrm{cm}^{3}$, Young's modulus of 2800-3500 MPa and a DSC melting point of $170-176^{\circ} \mathrm{C}$.

\section{Analytical Methods of Plasticizers Characteristic}

\section{Infrared Fourier Transformation (ATR-FTIR) Analysis}

The infrared spectra were recorded in a THERMO Scientific FTIR Nicolet Model 6700 spectrophotometer. The tests applied the reflection technique with (ATR), SMART ARK, using $\mathrm{ZnSe}$ crystals, the number of reflections $=7$, and the sample penetration depth by the IR beam $=0.11 \mu \mathrm{m}$.

\section{Gas Chromatography}

The GC/MS analysis were performed on a Hewlett Packard Model 7890 chromatograph equipped with a 7000 GC/ MS Triple Quad MS detector. The capillary column HT-5 $(\mathrm{l}=30 \mathrm{~m}$, diameter $=0.25 \mathrm{~mm}$, grain size of stationary phase $=0.25 \mu \mathrm{m}$ ) was used. The temperature-programmed mode from 70 to $380{ }^{\circ} \mathrm{C}$ was carried out. Helium was used as a carrier gas, at the flow rate of $2 \mathrm{ml} / \mathrm{min}$. The components were identified qualitatively by detailed interpretation of the mass spectra and - whenever possible — by matching spectra provided in the reference library NIST MS Search 2.0. The concentrations of particular groups of compounds (e.g. quantitative analysis) were established by internal standardization of the chromatographic peak areas, assuming that the correction factors were equal to 1.0. These analyzes were performed on a Hewlett-Packard series II5890 chromatograph with the capillary column HT-5, flame ionization detector (FID), sample injector and sample splitter.

\section{Thermogravimetric Analysis (TGA)}

A Mettler Toledo TGA 2 Thermobalance was used for the TG measurements. The samples were heated up in an open platinum crucible ( $\mathrm{Pt} 70 \mu \mathrm{l}$ without lid) in the temperature range $30-600{ }^{\circ} \mathrm{C}$ with a heating rate of $\beta=10^{\circ} \mathrm{C} / \mathrm{min}$ and in dynamic $(100 \mathrm{ml} / \mathrm{min})$ nitrogen atmosphere. The thermographs were analysed with the use of the STAR ${ }^{\mathrm{e}}$ Thermal Analysis Software (version 15.00).

\section{Physicochemical Characteristics}

The acid values of esters were found according to PN-EN 14104 while the iodine value of esters were determined according to the Standard PN-87/C-04281. In this method in the first step, the fatty acid ester is dissolved in the Kaufmann solution. The solution is left for a known time in the dark. In the next step potassium iodide is added and the liberated free iodine is titrated with thiosulphate.

The water content in esters was determined according to the Standard PN-ISO 760. These measurements were performed on a $870 \mathrm{KF}$ Titrino Plus titration assembly (Metrohm). The hydroxyl values of produced esters were analyzed according to DIN 53240. The Gardner colour specifications of esters were determined on a Lange Lico 4000 spectrophotometer.

\section{Analytical Methods of PHB-V Compounds Characteristic}

\section{Differential Scanning Calorimetry (DSC)}

To investigate the thermal behaviour of the compounds DSC analysis were performed with a Q2000 by TA Instruments using a temperature gradient of $10^{\circ} \mathrm{C} / \mathrm{min}$ from 0 to $200{ }^{\circ} \mathrm{C}$ (reference: empty Al pot). A preliminary heating cycle was used to delete the thermal history of the manufactured polymer compounds. The melting temperature $\left(\mathrm{T}_{\mathrm{m}}\right)$, crystallization temperature $\left(\mathrm{T}_{\mathrm{c}}\right)$ and melting enthalpy $\left(\Delta \mathrm{H}_{\mathrm{m}}\right)$ was determined. The evaluation of the degree of crystallization $\left(\mathrm{X}_{\mathrm{c}}\right)$ is calculated with Eq. 1: 
$X_{c}=\frac{\Delta H_{m}}{\Delta H_{m}^{0}} \cdot 100[\%]$

where $\Delta \mathrm{H}_{\mathrm{m}}$ is the measured specific melt enthalpy of the compound and $\Delta H_{m}^{0}$ is the melting enthalpy of the $100 \%$ crystalline polymer matrix (for $\mathrm{PHB}=109 \mathrm{~J} / \mathrm{g}$ ) [25].

\section{Mechanical Characterization}

The test specimens were conditioned before mechanical characterization for $24 \mathrm{~h}$ and 1 month at laboratory conditions $\left(23{ }^{\circ} \mathrm{C}, 50 \%\right.$ humidity). The tensile testing (DIN EN ISO 527-1) was performed using a controller 2 AC900 by Hegewald \& Peschke with a speed of $1 \mathrm{~mm} / \mathrm{min}$ up to $0.25 \%$ elongation and $50 \mathrm{~mm} / \mathrm{min}$ up to the break. Young's Modulus and tensile strength were investigated. The Charpy V-Notch impact test was performed with a Resil Impactor P/N 6957.000 by CEAST using notched (type A) and unnotched samples.

\section{Synthesis Procedures}

\section{Synthesis of Fatty Acids Methyl Esters}

Three different methyl ester samples were prepared: oleic acid methyl ester (ester 1), stearic acid (ester 2) and palmitic acid (ester 3 ). In order to obtain the esters the fatty acids esterification processes were carried out in a $2500 \mathrm{ml}$ laboratory glass reactor equipped with a mechanical stirrer, thermometer, nitrogen inlet tube and condenser. The esters were synthesized in several stages. At first methanol (240.0 g) and methanesulfonic acid (12.0 g) as a catalyst were added to oleic acid, stearic acid or palmitic acid (1200.0 g). The resulting mixture was then vigorously stirred and heated up to $70^{\circ} \mathrm{C}$ for $2 \mathrm{~h}$. After this time the temperature was raised to $80^{\circ} \mathrm{C}$ and under nitrogen environment the methanol and water formed during the esterification reaction were distilled out.

Afterwards the second step of esterification was carried out $\left(2 \mathrm{~h}, 70{ }^{\circ} \mathrm{C}\right)$. To initiate this reaction a mixture of a fresh portion of methanol $(240.0 \mathrm{~g})$ and methanesulfonic acid $(6.0 \mathrm{~g})$ were added. After $2 \mathrm{~h}$ the temperature was raised to $80{ }^{\circ} \mathrm{C}$ and under nitrogen environment, the methanol and water formed in the esterification reaction were distilled out. In the same way, subsequent stages of esterification were carried out. The acid values of reaction mixtures were adopted to control the progress of the esterification process. The esterification's steps were conducted until the acid number of reaction mixture reached $5 \mathrm{mg} \mathrm{KOH} / \mathrm{g}$. After the reaction was completed, the reaction mixture was subjected to purification.

The product was mixed with glycerol solution of $\mathrm{KOH}$ (10 wt \% on the ester feed) at $50{ }^{\circ} \mathrm{C}$ for $15 \mathrm{~min}$. The glycerol solution of $\mathrm{KOH}$ contained dissolved $\mathrm{KOH}$ in the amount calculated from the acid value (1.5-fold excess). The glycerol phase was separated by sedimentation $\left(4 \mathrm{~h}, 50^{\circ} \mathrm{C}\right)$. The ester phase was than washed twice with water $(3 \mathrm{wt} \%$ on the ester feed) at $50{ }^{\circ} \mathrm{C}$ for $15 \mathrm{~min}$. The aqueous phase was separated by sedimentation $\left(4 \mathrm{~h}, 50^{\circ} \mathrm{C}\right)$ and the ester phase was dried by purging with nitrogen at $105^{\circ} \mathrm{C}$.

\section{Synthesis of Fatty Acids and Ethylene Glycol Monoesters}

The four different ethylene glycol monoester samples, oleic acid, stearic acid, palmitic acid and lauric acid (ester 4-7) were prepared. Each of them was based on different fatty acid as fatty raw material. The fatty acids esterification process was carried out in a $2500 \mathrm{ml}$ laboratory glass reactor equipped with a mechanical stirrer, thermometer, nitrogen inlet tube and condenser. Each fatty acid was subjected to esterification with ethylene glycol at $120^{\circ} \mathrm{C}$ with methanesulfonic acid as a catalyst. The amount of reactants is shown in Table 1. The reactant mixture was vigorously stirred under nitrogen bubbling. Water formed in the esterification reaction was removed from the reaction mixture azeotropically with the use of toluene. The water/toluene azeotropic mixture was distilled out, condensed and collected in DeanStark trap. After a phase separation step the water phase was removed and the toluene phase was returned into reactor. The esterification reaction was monitored by sampling the reaction mixture for every $60 \mathrm{~min}$. The acid values of the samples were verified. The esterification was terminated when the acid reached values below $5 \mathrm{mg} \mathrm{KOH} / \mathrm{g}$. After the reaction was stopped, the reaction mixture was cooled down to room temperature and separated into two immiscible phases: the upper-ester and the bottom-containing mainly unreacted alcohol. The bottom phase was then removed and the upper phase was purified.

The product was washed sequentially with a saturated solution of $\mathrm{K}_{2} \mathrm{CO}_{3}(10 \mathrm{wt} \%$ on the ester feed) and with a saturated solution of $\mathrm{KCl}(10 \mathrm{wt} \%$ on the ester feed $)$ at $30^{\circ} \mathrm{C}$ for $15 \mathrm{~min}$. The aqueous phase was separated by sedimentation $\left(4 \mathrm{~h}, 30^{\circ} \mathrm{C}\right)$. The ester phase was than washed twice

Table 1 The starting compounds of the reaction mixture for the ethylene glycol monoesters formulations $(\mathrm{g})$

\begin{tabular}{lllll}
\hline Components $(\mathrm{g})$ & Ester 4 & Ester 5 & Ester 6 & Ester 7 \\
\hline Oleic acid & 790.0 & - & - & - \\
Stearic acid & - & 790.0 & - & - \\
Palmitic acid & - & - & 712.0 & - \\
Lauric acid & - & - & - & 503.4 \\
Ethylene glycol & 377.0 & 377.0 & 377.0 & 240.2 \\
Methanesulfonic acid & 2.32 & 2.32 & 2.09 & 1.48 \\
Toluene & 238.0 & 238.0 & 238.0 & 152.0 \\
\hline
\end{tabular}


with water ( $10 \mathrm{wt} \%$ on the ester feed) at $30{ }^{\circ} \mathrm{C}$ for $15 \mathrm{~min}$. The aqueous phase was separated by sedimentation $(4 \mathrm{~h}$, $30{ }^{\circ} \mathrm{C}$ ) and the ester phase was dried under vacuum at $80^{\circ} \mathrm{C}$.

\section{Compounding Procedures}

The synthesized esters as plasticizers have been compounded with PHB-V in 8,10 and $12 \mathrm{wt} \%$ ratio as previous internal studies have identified a limit of incorporation in the range $10-12 \mathrm{wt} \%$ for the investigated plasticizers. On the other hand these investigations showed that a loo low plasticizer content does not lead to the desired property improvements such as optimized ductility. As PHB-V is a very shear and temperature sensitive polymer, processing studies to identify the optimum processing conditions have been carried out and a soft screw design which additionally ensures a sufficient dispersion quality of the plasticizers was developed. Based on the results of this pre-investigation the materials were compounded with the co-rotating twin-screw extruder Leistritz Micro 27-36D using a rotation speed of $250 \mathrm{rpm}$ and a processing temperature of $150-175{ }^{\circ} \mathrm{C}$. Before injection moulding the granulates were pre-dried to avoid hydrolysis with Helios WINSystem dryers for $4 \mathrm{~h}$ at $80^{\circ} \mathrm{C}$. The measured moisture contents (AQUATRAC) were $0.08 \%$. The dried granulates were injection moulded with an Engel ES200/60 HL ST with a maximum clamping force of $600 \mathrm{kN}$ to Campus A tensile bars and Charpy impact test bars $(80 \times 10 \times 4) \mathrm{mm}^{3}$.

\section{Results and Discussion}

\section{Fatty Acid Composition}

For the synthesis of fatty acid esters used as PHB-V plasticizers, fatty raw materials differing in the fatty acid profile were used. In Table. 2 fatty acids which are included in the composition of the synthetized methyl esters and ethylene glycol esters determined by the GC method are listed.

Fatty acids available on the market are characterized by various lengths of hydrocarbon chains and various degrees of unsaturation. However the fatty raw materials used in this paper are characterized by very high contents of distinctive fatty acids of more than $90 \mathrm{wt} \%$ (Table 2), e.g. the product named as oleic acid contained $90.9 \mathrm{wt} \%$ oleic acid and product named as palmitic acid include $98.6 \mathrm{wt} \%$ of palmitic acid. Esters synthesized from such raw materials also will be characterized by the same narrow fatty acid profile. Therefore it will be possible to determine the influence of the structure of individual fatty acids on the properties of their methyl and ethylene glycol esters as PHB-V plasticizers.
Table 2 Chemical compositions of fatty acids used as plasticizers raw materials

\begin{tabular}{lllll}
\hline $\begin{array}{l}\text { Composition } \\
(w t \%)\end{array}$ & Oleic acid & Stearic acid & Palmitic acid & Lauric acid \\
\hline Fatty acid $\mathrm{C}_{12: 0}$ & - & - & - & 0.1 \\
Fatty acid $\mathrm{C}_{14: 0}$ & - & - & 0.1 & 99.7 \\
Fatty acid $\mathrm{C}_{16: 0}$ & 0.9 & 3.7 & 98.6 & 0.1 \\
Fatty acid $\mathrm{C}_{18: 0}$ & 2.0 & 92.7 & 0.3 & - \\
Fatty acid $\mathrm{C}_{18: 1}$ & 90.9 & 1.1 & - & - \\
Fatty acid $\mathrm{C}_{18: 2}$ & 3.8 & - & - & - \\
Fatty acid $\mathrm{C}_{18: 3}$ & - & - & - & - \\
Fatty acid $\mathrm{C}_{20: 0}$ & 0.7 & - & - & - \\
Fatty acid $\mathrm{C}_{20: 1}$ & 0.3 & - & - & - \\
Other & 1.4 & 2.5 & 1.0 & - \\
\hline
\end{tabular}

\section{Properties of Fatty acid Esters}

The physical and chemical properties of synthesized esters of fatty acids which were used as plasticizers were presented in Table 3.

All analysed fatty acids esters are characterised by low water content, below $0.05 \%$, light color, below 5.1 in Gardner scale and low acid value below $2 \mathrm{mg} \mathrm{KOH} / \mathrm{g}$ (Table 3). Only for ester 5 acid value was found somewhat higher- $3.30 \mathrm{mg} \mathrm{KOH} / \mathrm{g}$. However, it seems that this amount of free fatty acids is still relatively low and shouldn't affect the efficiency of this ester as a plasticizer. Ester 1 similarly to ester 4 is characterized by higher than other esters iodine value, respectively $77.6 \mathrm{~g} \mathrm{I}_{2} / 100 \mathrm{~g}$ and $75.7 \mathrm{~g} \mathrm{I}_{2} / 100 \mathrm{~g}$, cause both of them were obtained by oleic acid esterification. This fatty acid contains one unsaturated bond in the hydrocarbon chain while other used fatty acids are saturated types. As expected, in the case of ethylene glycol monoesters, the obtained hydroxyl value was high, in range $136.0-144.0 \mathrm{mg} \mathrm{KOH} / \mathrm{g}$.

The produced esters were also analyzed by GC/MS and GC/FID. Table 4 shows the chemical compositions of the analyzed esterification products.

The analyzed esters 1-3 contain more than $95 \mathrm{wt} \%$ of fatty acid methyl esters (Table 4). Esters 4-7 on the other hand both contain ethylene glycol monoesters of fatty acids (69.3-77.8 wt\%) and ethylene glycol diesters of fatty acids (18.6-29.3 wt\%). It is possible to obtain ethylene glycol monoesters with higher purity, however, this requires the use of severe distillation conditions. All analysed samples contain a similar amount of ethylene glycol mono- and diesters, which makes it possible to compare the effect of the fatty acid type on their properties as a PHB-V plasticiser, which is one key interest of the research within this paper. An additional aspect is the cost of plasticizer production. Distillation step would 
Table 3 Physicochemical properties of fatty acids esters

\begin{tabular}{llllclcc}
\hline Properties & Ester 1 & Ester 2 & Ester 3 & Ester 4 & Ester 5 & Ester 6 & Ester 7 \\
\hline Color (gardner scale) & 1.1 & 0.4 & 0.1 & 5.1 & 1.4 & 0.4 & 1.3 \\
Acid value $(\mathrm{mg} \mathrm{KOH} / \mathrm{g})$ & 0.31 & 0.98 & 0.25 & 1.16 & 3.30 & 1.60 & 1.30 \\
Iodine value $(\mathrm{g} \mathrm{I} / \mathrm{l} / \mathrm{g}$ g) & 77.60 & 0.10 & 0.05 & 75.70 & 0.12 & 0.11 & 0.10 \\
Hydroxyl value $(\mathrm{mg} \mathrm{KOH} / \mathrm{g})$ & - & - & - & 130.1 & 144.0 & 136.0 & 141.0 \\
Water content $(\mathrm{wt} \%)$ & 0.001 & 0.001 & 0.029 & 0.045 & 0.050 & 0.032 & 0.046 \\
Kinematic viscosity at $60^{\circ} \mathrm{C}\left(\mathrm{mm}^{2} / \mathrm{s}\right)$ & 3,61 & 3.98 & 3.02 & 11.34 & Solid* & 18.99 & 6.20 \\
Density at $60^{\circ} \mathrm{C}\left(\mathrm{g} / \mathrm{cm}^{3}\right)$ & 0.853 & 0.840 & 0.841 & 0.894 & Solid* & 0.895 & 0.896 \\
\hline
\end{tabular}

*The sample is solid at $60{ }^{\circ} \mathrm{C}$

\begin{tabular}{llllllll}
\hline Compositions (wt\%) & Ester 1 & Ester 2 & Ester 3 & Ester 4 & Ester 5 & Ester 6 & Ester 7 \\
\hline Ethylene glycol & - & - & - & - & 0.1 & 0.9 & 0.2 \\
Free fatty acids & 0.6 & 1.1 & 0.6 & 0.7 & 2.8 & 1.8 & 0.7 \\
Fatty acids methyl esters & 95.9 & 95.7 & 98.3 & - & - & - & - \\
Ethylene glycol monoesters & - & - & - & 77.5 & 77.8 & 72.9 & 69.3 \\
Ethylene glycol diesters & - & - & - & 21.6 & 18.6 & 24.0 & 29.3 \\
Other & 3.5 & 3.2 & 1.1 & 0.2 & 0.7 & 0.4 & 0.5 \\
\hline
\end{tabular}

Table 4 Compositions (wt \%) of the fatty acids esters by GC/MS and GC/FID contribute to increasing their production costs and higher plasticizer price.

The structures of esterification products were also confirmed by FT-IR spectroscopy. The example of FT-IR spectra for fatty acids methyl esters was shown in Fig. 2 and for ethylene glycol monoesters of fatty acids in Fig. 3.

The FT-IR spectra of obtained fatty acids esters (ester 1-7) are similar. The stretching vibrations corresponding to: groups C-H of alkane at $2918-2854 \mathrm{~cm}^{-1}$ (Figs. 2, 3), $\mathrm{C}=\mathrm{O}$ of ester groups at $1742-1744 \mathrm{~cm}^{-1}$ (Fig. 2) and $1739-1741 \mathrm{~cm}^{-1}$ (Fig. 3) and $\mathrm{C}-\mathrm{O}$ bond in of ester groups at $1170-1175 \mathrm{~cm}^{-1}$ (Fig. 2) and $1174-1180 \mathrm{~cm}^{-1}$ (Fig. 3) are observed in FT-IR spectra for all synthesized esters. The deforming vibrations corresponding to: groups $\mathrm{C}-\mathrm{H}$ of alkane at $1464-1473 \mathrm{~cm}^{-1}$ (Fig. 2) and $1463-1473 \mathrm{~cm}^{-1}$ (Fig. 3) are present in FT-IR spectra for all synthesized esters. The main difference in the FT-IR spectra between esters 1-3 and esters 4-7 is related to the presence a strong band at $3445-3461 \mathrm{~cm}^{-1}$ (Fig. 3) of ethylene glycol monoesters corresponding to the $\mathrm{O}-\mathrm{H}$ group stretching vibrations. This band is not present in the FT-IR spectra of analyzed fatty acid methyl esters (Fig. 2).

The FT-IR spectra of ester 1 and ester 4 unlike other analysed samples of the fatty acid esters have absorption bands respectively at $3009 \mathrm{~cm}^{-1}$ (Fig. 2) and at $3004 \mathrm{~cm}^{-1}$ (Fig. 3) which correspond to $\mathrm{C}-\mathrm{H}$ stretching and deformation vibrations in unsaturated $-\mathrm{HC}=\mathrm{CH}-$ bonds, and at $1654 \mathrm{~cm}^{-1}$ (Fig. 2) and at $1658 \mathrm{~cm}^{-1}$ (Fig. 3) which correspond to $\mathrm{C}=\mathrm{C}$ stretching vibrations. The presence of these bands clearly indicates the presence of unsaturated $\mathrm{C}=\mathrm{C}$ bonds in the chemical structure of this esters. This is due to the main component of the ester 1 and ester 4 is ester of oleic acid.

One of the significant factors which determines whether the chemical compound is useful as plasticizer is the thermal stability during PHB-V processing $\left(170-180{ }^{\circ} \mathrm{C}\right)$. The TGA analysis were conducted to obtained the information about the decomposition behavior of the produced esters. The thermal degradation of the esters 1-7 was investigated by TGA in nitrogen atmosphere, at a heating rate of $10{ }^{\circ} \mathrm{C} /$ min. The TG and DTG curves are shown in Figs. 4 and 5. The temperatures required for reaching certain weight losses (wt\%) are given in Table 5.

As shown in Figs. 4 and 5, the characteristics of methyl esters of fatty acids and ethylene glycol esters of fatty acids are diversified. The weight of the methyl esters of fatty acids starts to decrease (5\% weight loss) at $161.4{ }^{\circ} \mathrm{C}$ for ester 3 and at $180.3{ }^{\circ} \mathrm{C}$ and $182.8{ }^{\circ} \mathrm{C}$ respectively for ester 1 and ester 2 . The $10 \%$ weight losses for ester 1 , ester 2 and ester 3 occurred respectively at $199.9^{\circ} \mathrm{C}, 202.3^{\circ} \mathrm{C}$ and $181.9^{\circ} \mathrm{C}$. It continues to decrease until all the fatty acids methyl esters present in the analysed sample are vaporized. Ester 3 is palmitic acid methyl ester and is characterised by shorter hydrocarbon chain than ester 1 and ester 2-respectively oleic acid methyl ester and stearic acid methyl ester. It corresponds to its higher volatility and it is the reason that a 5\% weight loss and $10 \%$ weight loss of ester 3 occurs at a lower temperature than for ester 1 and 2.

From the Fig. 4, it can be observed that for esters 1-3 one peakpoint of the DTG curves occurred. It is corresponding to evaporation of fatty acid methyl esters. This is a typical behaviour for this type of chemical compounds. 


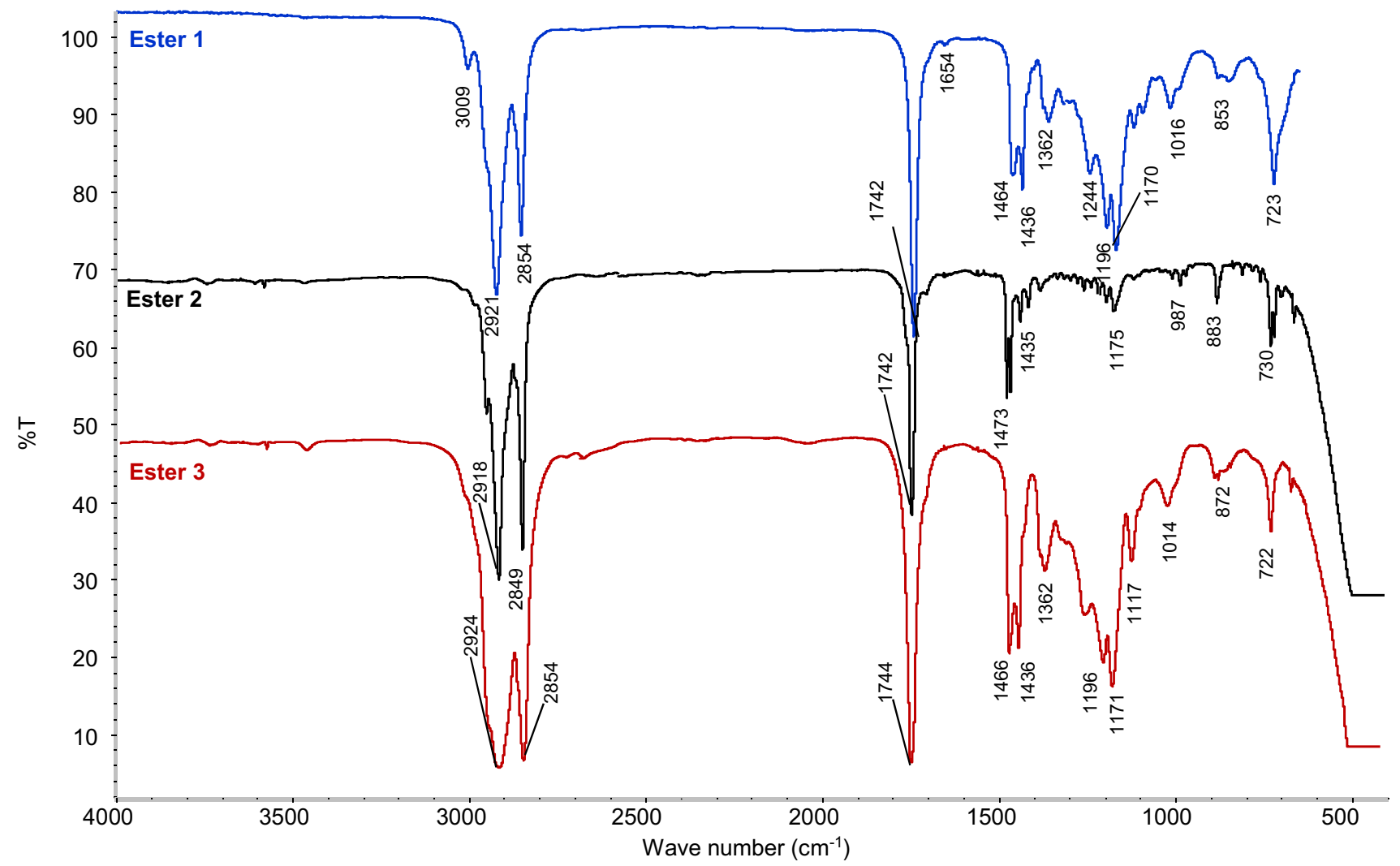

Fig. 2 FT-IR spectra for ester 1 (oleic acid methyl ester), ester 2 (stearic acid methyl ester) and ester 3 (palmitic acid methyl ester)

Ethylene glycol fatty acid esters are characterized by a higher boiling point compared to fatty acids methyl esters. Therefore their weight starts to decrease at higher temperature than for the analysed fatty acid methyl esters (Table 5). The 5\% weight loss of ethylene glycol esters of oleic acid (ester 4) and stearic acid (ester 5) took place at the temperature $229.1{ }^{\circ} \mathrm{C}$ respectively $229.6{ }^{\circ} \mathrm{C}$. On the other hand, for ethylene glycol esters of shorten fatty acids with lower boiling points like palmitic acid (ester 6) and lauric acid (ester 7) the 5\% weight loss took place at the significantly lower temperature $210.1{ }^{\circ} \mathrm{C}$ respectively $181.0^{\circ} \mathrm{C}$.

On the DTG curves of esters 4-7 (Fig. 5) two peakpoints are observed where the maximum rate of thermal decomposition took place. Probably it is a combination of two processes evaporation of both ethylene glycol monoesters and ethylene glycol diesters as well as aliphatic chain thermal degradation which is starting about $300{ }^{\circ} \mathrm{C}$.

The results of TGA analysis indicate that all synthesized esters are characterized by a sufficient thermal stability and low volatility in the measured temperature range. Typically the processing temperature of these plasticizers do not exceed $180{ }^{\circ} \mathrm{C}$ due to the temperature sensitivity of the PHB-V.

\section{Compatibility Between PHB-V and Plasticizers}

First condition for using an ester as a plasticizer of biopolymer products is its miscibility and compatibility with the biopolymer. The synthesized esters (plasticizers) have been compounded with PHB-V in 8, 10 and $12 \mathrm{wt} \%$ ratio. For each The test plan of the research is summarized in Table 6 .

The results show, that not all PHB-V compounds could be produced due to incompatibility between the polymer melt and the plasticizer, which resulted in an inhomogeneous melt flow and phase separation. For ester 2 the incompatibility already occurred at $8 \mathrm{wt} \%$ plasticizer ratio. The limit for the esters $1,3,5$ and 6 was $10 \mathrm{wt} \%$, while for the esters 4 and 7 the maximum for the plasticizers dosing was identified in the range of $8 \mathrm{wt} \%$. In Fig. 6 the phase separation effects of the polymer melt and plasticizer which have been taken place during compounding are shown (a) at extruder die position and (b) in the degassing port.

The obtained results indicate how the structure of the plasticizer influences the compatibility between plasticizer with the polymer. Comparing ester 1 and ester 2 namely the methyl esters of oleic acid and the methyl esters of stearic acid these compounds differ only in the presence of one unsaturated bond in the fatty acid hydrocarbon chain. The compounding results show that ester 1 which contain 


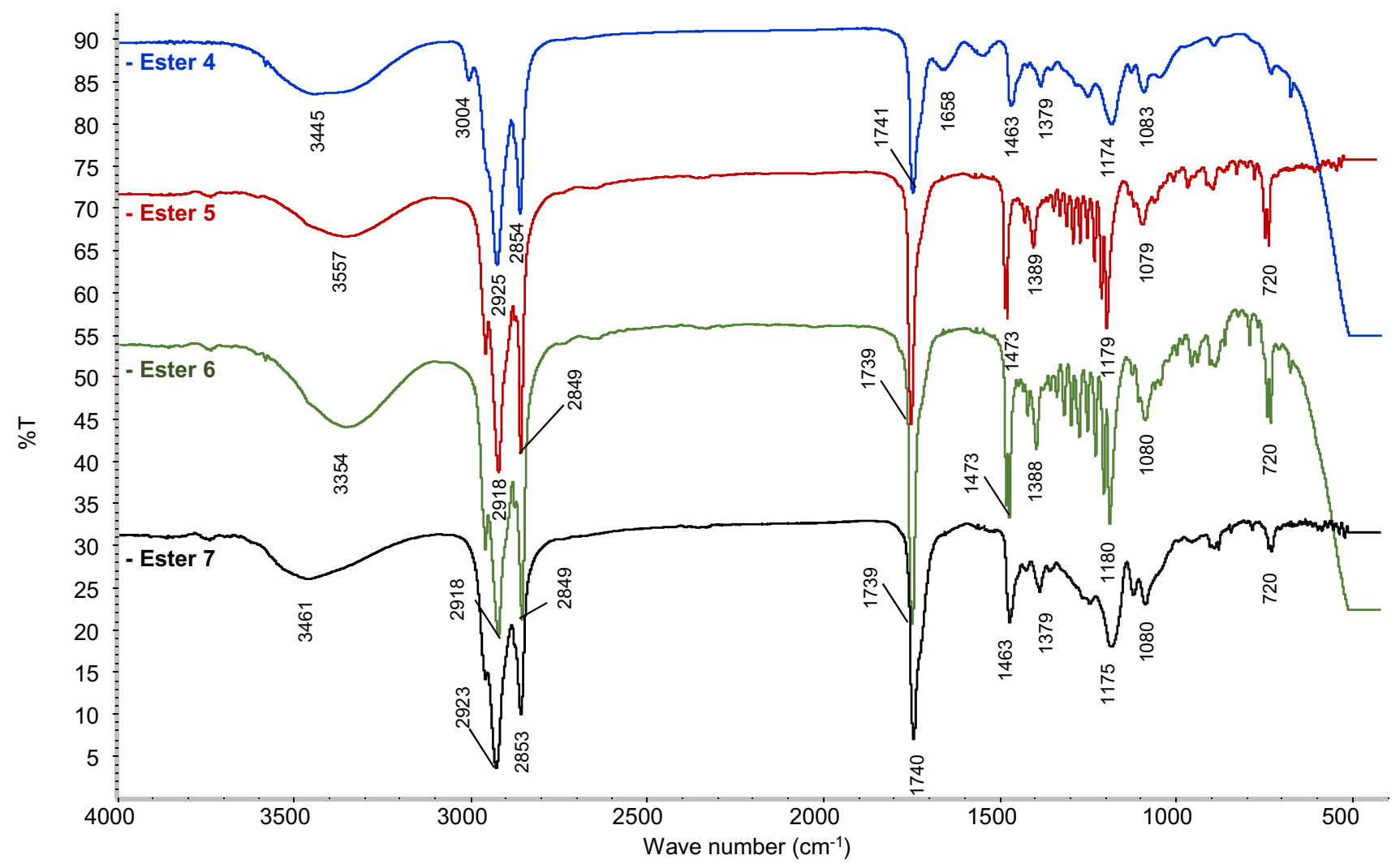

Fig. 3 FT-IR spectra for ester 4 (oleic acid ethylene glycol monoester), ester 5 (stearic acid ethylene glycol monoester), ester 6 (palmitic acid ethylene glycol monoester) and ester 7 (lauric acid ethylene glycol monoester)
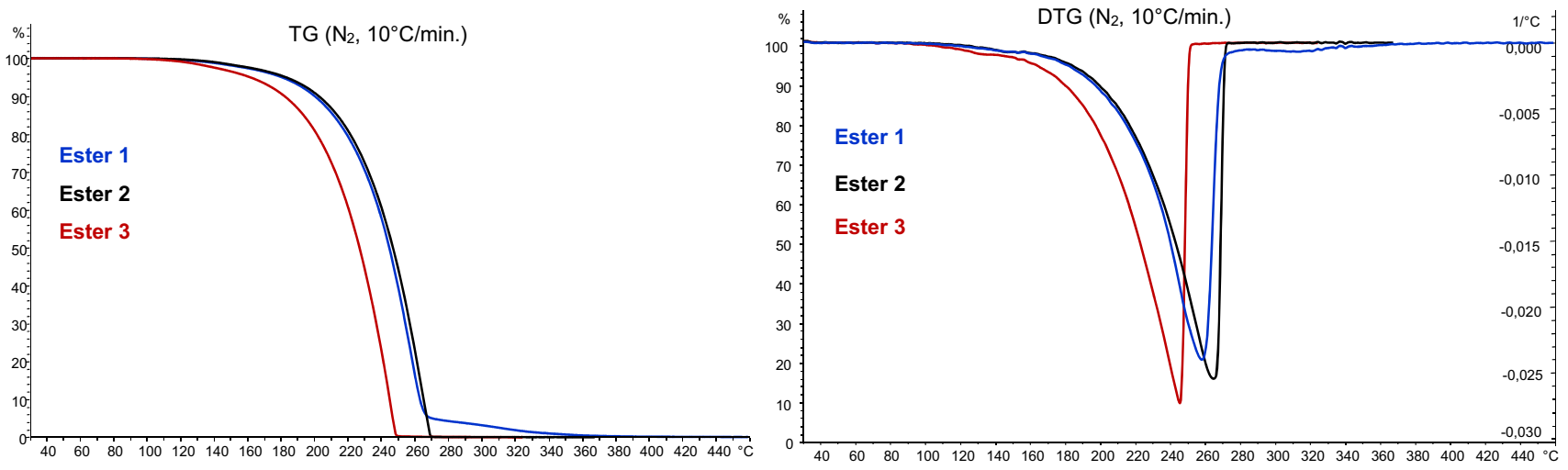

Fig. 4 The TG and DTG curves of ester 1 (oleic acid methyl ester), ester 2 (stearic acid methyl ester) and ester 3 (palmitic acid methyl ester)

the unsaturated bond in the fatty acid hydrocarbon chain is compatible with the polymer and can be compounded with PHB-V in up to $10 \mathrm{wt} \%$ ratio. While for saturated ester 2 even $8 \mathrm{wt} \%$ is already overdosed (immiscible) and therefore not processable. The compared esters only differ slightly in terms of molecular weight, however, the presence of unsaturated bonds significantly affects their physicochemical properties and spatial arrangement of hydrocarbon chain. Stearic acid methyl ester is solid at room temperature with high melting point and its molecules have perfectly straight chain structure (Fig. 7a). Oleic acid methyl ester on the other hand is liquid at room temperature with lower melting point and its chain structure is bent (Fig. 7b). These factors may be the reason for differences in the miscibility of the tested esters with PHB-V and affect their effectiveness as plasticizers. 

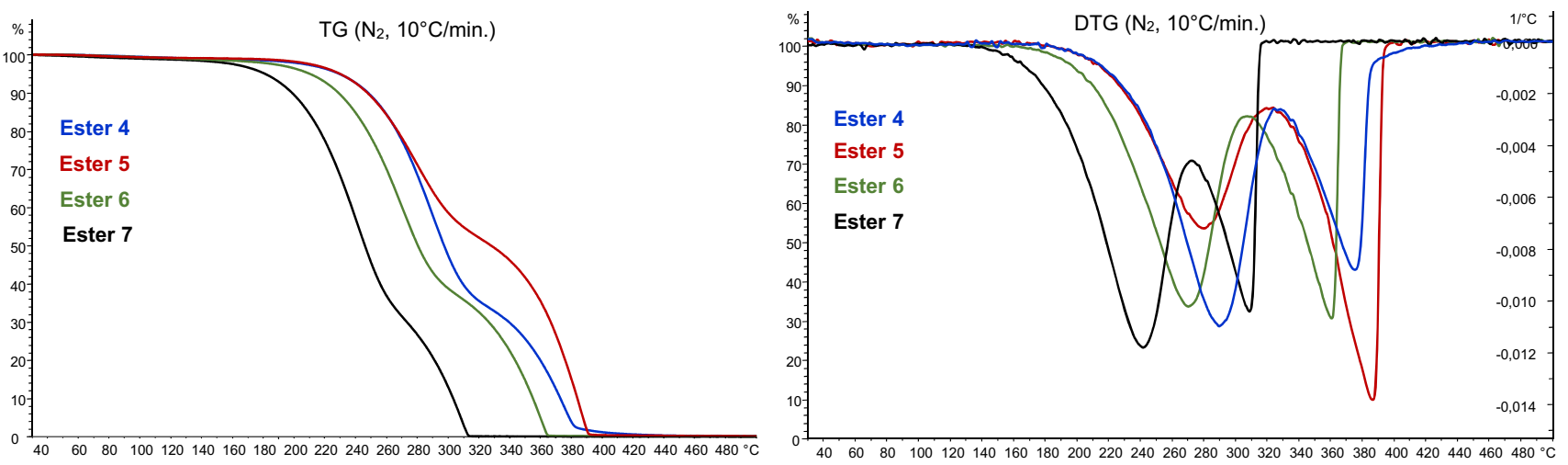

Fig. 5 The TG and DTG curves of ester 4 (oleic acid ethylene glycol monoester), ester 5 (stearic acid ethylene glycol monoester), ester 6 (palmitic acid ethylene glycol monoester) and ester 7 (lauric acid ethylene glycol monoester)

Table 5 Temperatures required for reaching certain weight losses (wt $\%)$

\begin{tabular}{lll}
\hline Fatty acids esters & $\mathrm{T}_{5 \%}\left({ }^{\circ} \mathrm{C}\right)$ & $\mathrm{T}_{10 \%}\left({ }^{\circ} \mathrm{C}\right)$ \\
\hline Ester 1 & 180.3 & 199.9 \\
Ester 2 & 182.8 & 202.3 \\
Ester 3 & 161.4 & 181.9 \\
Ester 4 & 229.1 & 248.0 \\
Ester 5 & 229.6 & 247.5 \\
Ester 6 & 210.1 & 228.8 \\
Ester 7 & 181.0 & 198.6 \\
\hline
\end{tabular}

Analyzing the miscibility of the other esters with PHB-V, it can be stated that ester 3 e.g. palmitic acid methyl ester can be compounded with PHB-V in up to $10 \mathrm{wt} \%$. Ester 3 is characterized by physicochemical properties and spatial arrangement of hydrocarbon chain analogous to the stearic acid methyl ester but its molecular weight is lower. It can be assumed that for saturated fatty acids methyl esters this parameter determines miscibility and compatibility with the PHB-V.

However, this doesn't mean that stearic acid cannot be used as a raw material for the production of PHB-V plasticizers. Stearic acid ethylene glycol monoester (ester 4) can be compounded with PHB-V in $10 \mathrm{wt} \%$ ratio in the same ratio as oleic acid methyl ester (ester 1). Probably the presence of a free hydroxyl group significantly changes the properties of the ester and increases the miscibility. It can be assumed that the free hydroxyl group forms hydrogen bonds with the carbonyl groups of the polyester and thus enhances the compatibility of the plasticizer with the polymer.

To some extent a similar effect occurs in the case of palmitic acid. Palmitic acid methyl ester is compatible with the polymer with a maximum ratio of $8 \mathrm{wt} \%$, while its monoester with ethylene glycol can be mixed with the polymer up to an amount of $10 \mathrm{wt} \%$.
Table 6 Compounding test campaign of the plasticized PHB-V compounds

\begin{tabular}{|c|c|c|c|}
\hline Compound name & Plasticizer & Ratio (wt\%) & $\begin{array}{l}\text { Process- } \\
\text { able (yes/ } \\
\text { no) }\end{array}$ \\
\hline PHB-V & - & - & Yes \\
\hline C 1 & Ester 1 & 8.0 & Yes \\
\hline $\mathrm{C} 2$ & Ester 1 & 10.0 & Yes \\
\hline C 3 & Ester 1 & 12.0 & No \\
\hline $\mathrm{C} 4$ & Ester 2 & 8.0 & No \\
\hline C 5 & Ester 2 & 10.0 & No \\
\hline C 6 & Ester 2 & 12.0 & No \\
\hline $\mathrm{C} 7$ & Ester 3 & 8.0 & Yes \\
\hline $\mathrm{C} 8$ & Ester 3 & 10.0 & Yes \\
\hline C 9 & Ester 3 & 12.0 & No \\
\hline C 10 & Ester 4 & 8.0 & Yes \\
\hline C 11 & Ester 4 & 10.0 & No \\
\hline C 12 & Ester 4 & 12.0 & No \\
\hline C 13 & Ester 5 & 8.0 & Yes \\
\hline C 14 & Ester 5 & 10.0 & Yes \\
\hline C 15 & Ester 5 & 12.0 & No \\
\hline C 16 & Ester 6 & 8.0 & Yes \\
\hline C 17 & Ester 6 & 10.0 & Yes \\
\hline C 18 & Ester 6 & 12.0 & No \\
\hline C 19 & Ester 7 & 8.0 & Yes \\
\hline C 20 & Ester 7 & 10.0 & No \\
\hline $\mathrm{C} 21$ & Ester 7 & 12.0 & No \\
\hline
\end{tabular}

The opposite is observed for oleic acid, namely its monoesters with ethylene glycol are compatible with PHB-V only at ratio of $8 \mathrm{wt} \%$, which is lower than its methyl esters (10 wt \%). The reason is most likely connected to oleic acid monoesters with ethylene glycol hydrocarbon chain structure and their molecular mass. Plasticizer molecules are thought to embed themselves between the chains of PHB-V, spacing the polyester molecules apart and thus increasing the "free 
Fig. 6 Phase separation effects of the polymer melt and plasticizer a at extruder die position and $\mathbf{b}$ in the degassing port

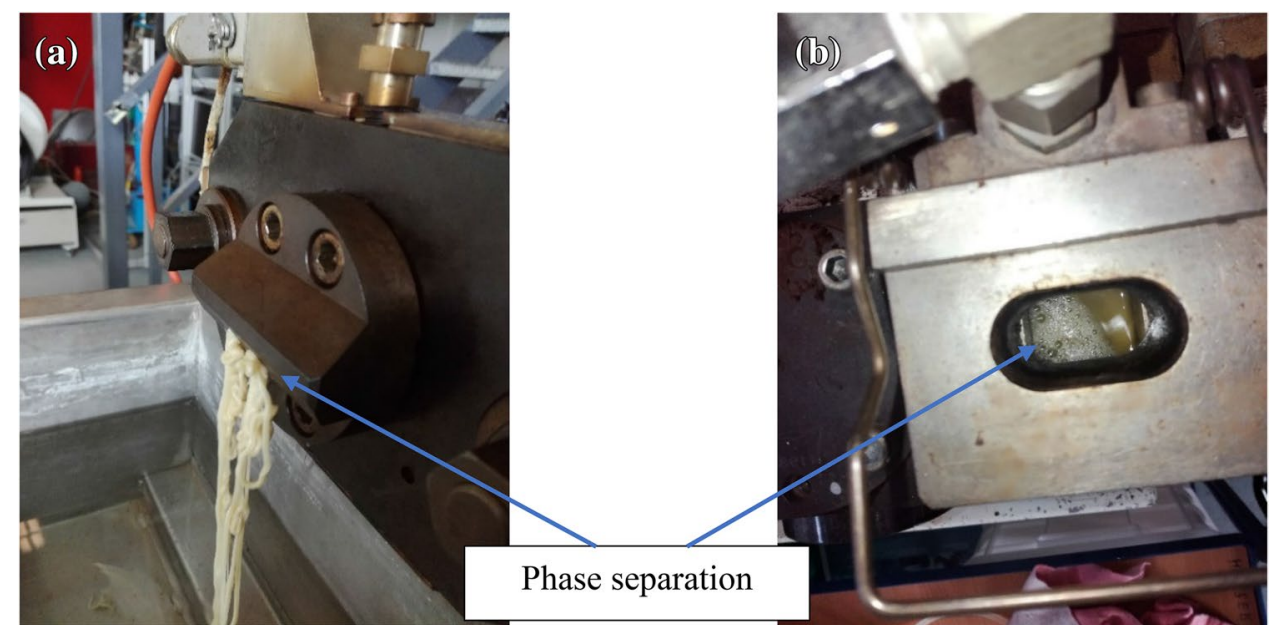

volume". Esters of unsaturated fatty acids due to bent hydrocarbon chain structure probably can create "free volume" in sizes that make it difficult to form hydrogen bonds between free hydroxyl groups of plasticizer and the carbonyl groups of the polyester. Therefore, the presence of free functional groups does not improve the compatibility between this plasticizer and PHB-V. In addition, the molar mass of ethylene glycol monoester is significantly higher than the corresponding methyl ester, which probably negatively affects their miscibility.

When the plasticizer with linear chains and free hydroxyl groups, like palmitic acid monoester with ethylene glycol, penetrates through the polymer matrix the created "free volume" is smaller and it's easier to form hydrogen bonds with the carbonyl groups of the polyester.

It seems that in order to achieve the expected plasticizer and PHB compatibility, it is necessary to adapt three elements of plasticizer characteristic: spatial structure,

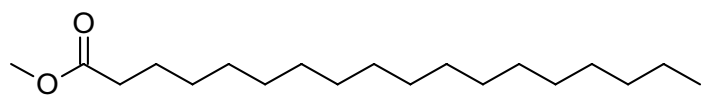

(a)

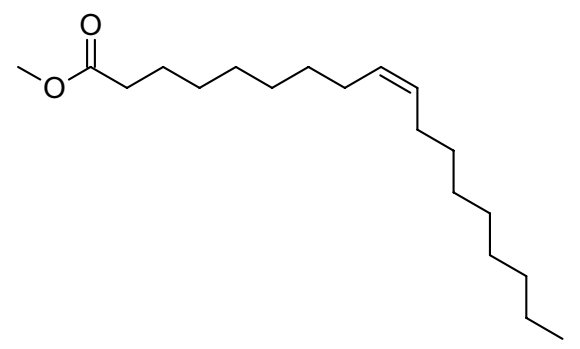

(b)

Fig. 7 Spatial arrangement of hydrocarbon chain of the stearic acid methyl ester (a) and oleic acid methyl ester (b) molecular weight and the content of functional groups in this case free hydroxyl groups.

\section{Non-isothermal Crystallization Kinetics}

All samples were preliminary heated at $10{ }^{\circ} \mathrm{C} / \mathrm{min}$ to clear their thermal history. The DSC-thermogram is showing the first cooling and the second heating cycle of neat PHB-V, $\mathrm{C} 1$ and $\mathrm{C} 2$ with a heating/cooling rate of $10{ }^{\circ} \mathrm{C} / \mathrm{min}$ in the range of 0 and $220^{\circ} \mathrm{C}$, see Fig. 8 .

The investigation shows that the implementation of the ester 1 in a PHB-V matrix reduces the crystallization and melting temperature. Simultaneously the melt enthalpy $\left(\Delta \mathrm{H}_{\mathrm{m}}\right)$ and the degree of crystallization $\left(\mathrm{X}_{\mathrm{c}}\right)$ increases when comparing with the neat PHB-V sample. This indicates that the plasticizers adversely affect the crystallization kinetics of PHB-V, tending to result in a lower crystallization temperature compared to the reference sample. However generally the values of the melting enthalpy are not markedly effected by the use of plasticizers which results in a similar crystallization rate of the plasticized PHB-V compounds compared to the neat PHB-V. Comparing the processing conditions of the neat and plasticized samples no significant difference can be observed. In Table 7 a summary of the data derived by the DSC-analysis for selected samples is presented.

\section{Mechanical Properties}

The compounded samples were processed with an Engel ES200/60 HL ST injection moulding machine to Campus A tensile bars and Charpy impact test bars. Before testing all samples were conditioned at $23{ }^{\circ} \mathrm{C}$ and $50 \%$ humidity for 1 day and respectively 1 month to investigate the aging effect. The investigation on mechanical properties in this paper refers to tensile strength, Young's modulus, Charpy impact strength (unnotched) and strain at break of the 


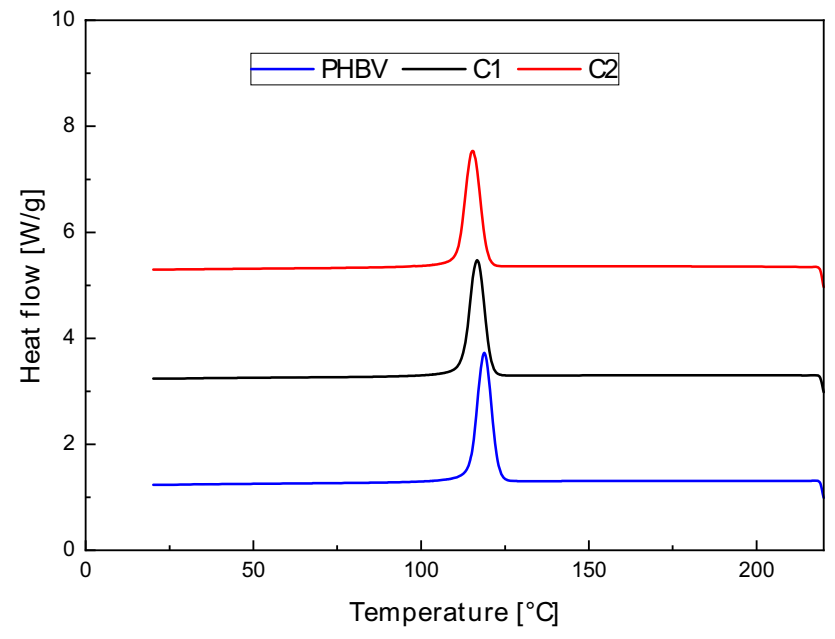

(a)

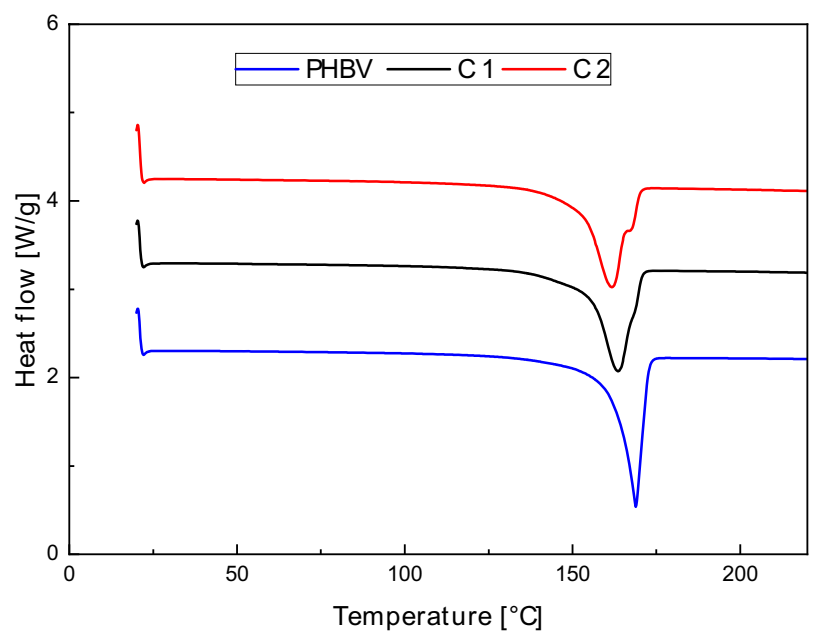

(b)

Fig. 8 DSC-analysis results for C 1 and C 2 in comparison to neat PHB-V, a first cooling scan, b second heating scan

Table 7 Results of the DSC-analysis for some specific PHB-V-compounds

\begin{tabular}{lllll}
\hline Compound name & $\mathrm{T}_{\mathrm{c}}\left({ }^{\circ} \mathrm{C}\right)$ & $\mathrm{T}_{\mathrm{m}}\left({ }^{\circ} \mathrm{C}\right)$ & $\Delta \mathrm{H}_{\mathrm{m}}(\mathrm{J} / \mathrm{g})$ & $\mathrm{X}_{\mathrm{c}}(\%)$ \\
\hline PHB-V & 118.8 & 168.8 & 75.4 & 69.2 \\
$\mathrm{C} 1$ & 116.7 & 163.7 & 76.1 & 69.8 \\
$\mathrm{C} 2$ & 115.3 & 161.8 & 76.9 & 70.6 \\
\hline
\end{tabular}

$\Delta H_{m}^{0}=$ melting enthalpy of $100 \%$ crystalline PLA $109 \mathrm{~J} / \mathrm{g}$ [25]

plasticized samples. In Fig. 9 the results of the mechanical tests are shown.

The results clearly show, that the esters generally increase the impact strength of the notches samples after 1 day conditioning time before testing. In comparison to the neat PHB-V the increase in ductility is in the range of $28-193 \%$. However, depending on the structure of individual plasticizers, these parameters differ significantly from each other. The best Charpy notched values have been observed for sample $\mathrm{C}$ 7 and $\mathrm{C} 19$ with $4.0 \mathrm{~kJ} / \mathrm{m}^{2}$ and respectively $4.1 \mathrm{~kJ} / \mathrm{m}^{2}$ in case of using the plasticizers with the shortest hydrocarbon chain length, namely palmitic acid methyl ester (C 7) and lauric acid ethylene glycol monoester (C 19) at a ratio of $8 \mathrm{wt} \%$.

A similar effect depending on the plasticizers can also be observed in the elongation at break properties of the compounds. The results show an increase in the elongation at break properties of the samples after 1 day conditioning time before testing. In comparison to the virgin PHB-V the increase in elongation is depending on the structure of individual plasticizers in the range of $19-79 \%$. The best elongation at break properties have been observed for sample $\mathrm{C} 1$, C10 and C 19 with $6.8 \%, 6.7 \%$ and respectively $6.4 \%$. For all samples $8 \mathrm{wt} \%$ plasticizer was added.
Probably small linear molecules of lauric acid and palmitic acid esters, can easily penetrates through the polymer matrix. Additionally lauric acid monoester with ethylene glycol can form hydrogen bonds with the carbonyl groups of the polyester thus reduce intermolecular bonds among polymer chains. It is also possible that during PHB-V processing plasticizer free hydroxyl groups can form covalent bonds with the carboxyl groups of the polyester. The condensation reaction between the hydroxyl groups and the carboxyl groups present in the PHB at $180{ }^{\circ} \mathrm{C}$ is also mentioned by Grassie et al. [26]. However, it should be noted that the amount of available free carboxyl groups in PHB-V macromolecules is very low. Therefore their impact on PHB-V compound mechanical properties would be rather minimal.

It can be concluded that the ester molecules of plasticizers with the linear structure and low molecular weight allow to get the best Charpy notched results, even better if they contain a free hydroxyl group.

An analogous result was obtained when using oleic acid methyl ester with longer hydrocarbon chain but containing unsaturated bond as a plasticizer. This plasticizer compounded with PHB-V at a ratio of $8 \mathrm{wt} \%$ (C 1) gave $3.7 \mathrm{~kJ} /$ $\mathrm{m}^{2}$ Charpy notched value while at a ratios of $10 \mathrm{wt} \%$ (C 2) the Charpy notched value was even $4.0 \mathrm{~kJ} / \mathrm{m}^{2}$. Oleic acid methyl ester is characterized by higher molecular weight than previous esters, its hydrocarbon chain structure is bent due to presence unsaturated bond. This time reduction intermolecular bonds among polymer chains is probably achieved by their interactions with oleic acid methyl ester hydrocarbon chain.

The lowest Charpy notched value of $1.8 \mathrm{~kJ} / \mathrm{m}^{2}$ and lowest elongation at break value of $4.5 \%$ of was observed for the sample C 13 in which the plasticizer stearic acid ethylene 


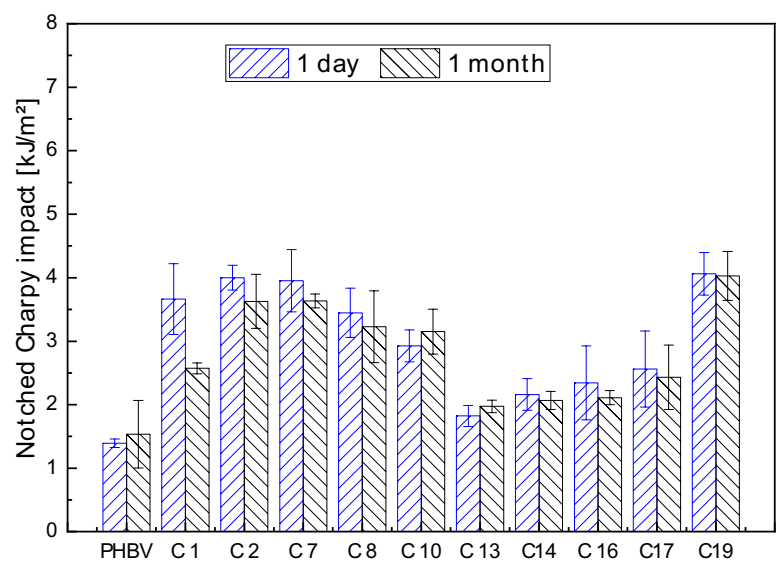

(a)

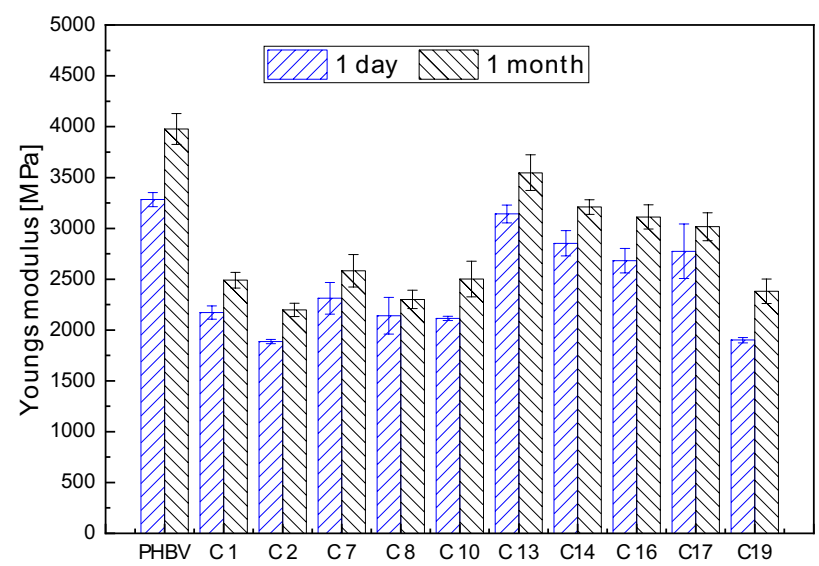

(c)

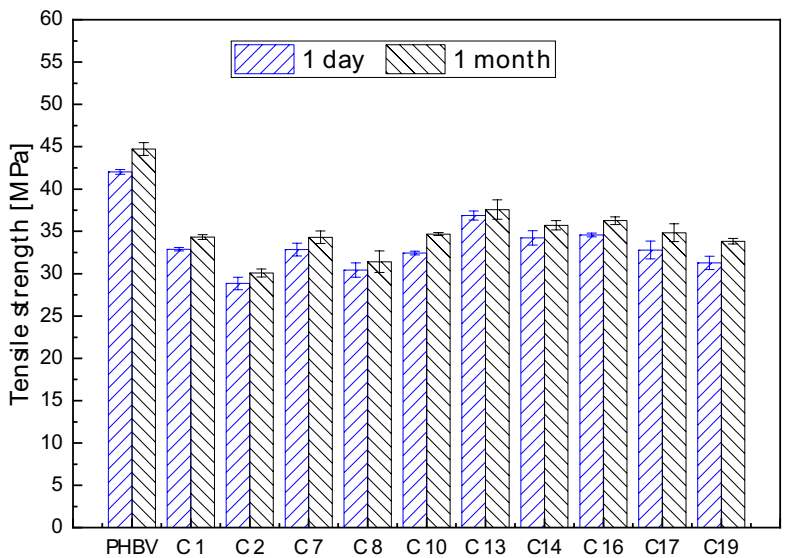

(b)

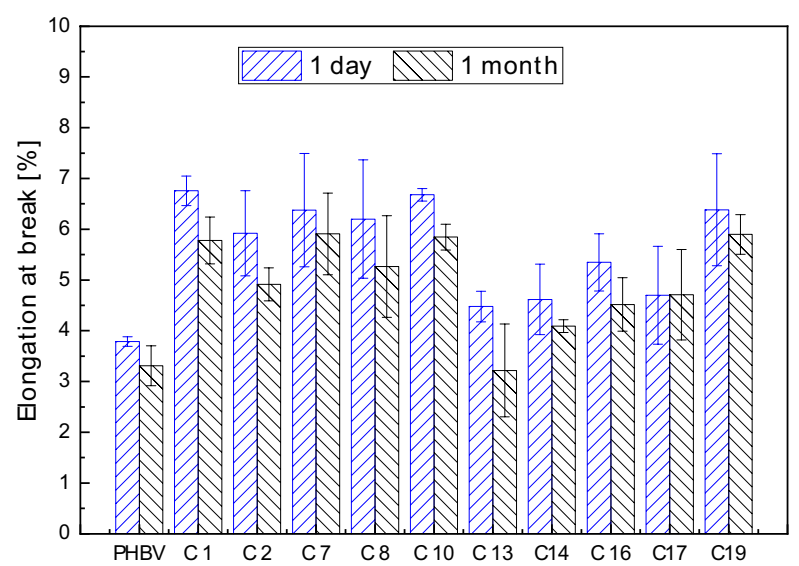

(d)

Fig. 9 Mechanical test results after 1 day and 1 month, a Charpy impact strength, b tensile strength and c Young's modulus, $\mathbf{d}$ elongation at break

glycol monoester was used (conditioning time 1 day). This plasticizer is characterized by the largest hydrocarbon chain length and is a saturated compound compared to the previous presented. For its shorter analogue-stearic acid ethylene glycol monoester with the same dose of plasticizer (C 16) a visibly better result of the Charpy notched value of $2.3 \mathrm{~kJ} / \mathrm{m}^{2}$ and elongation at break value of 5.3\% was obtained.

The presented results for the impact and elongation at break properties indicate that even small differences in the structure of the individual plasticizers have a positive effect on the characteristics of the final PHB-V compound.

In terms of tensile strength and Young's modulus values the effect of the plasticizer structure on the properties of the PHB-V compound also can be detected. However in contrast to the impact strength the tensile strength properties decrease with increasing plasticizer content from initially $42 \mathrm{MPa}$ in the range of $12-31 \%$ and Young's modulus values from $3283 \mathrm{MPa}$ about $4-42 \%$. The highest tensile strength and Young's modulus values gives sample C 13 with a tensile strength value of $36.9 \mathrm{MPa}$ and a Young's modulus of $3142 \mathrm{MPa}$. In this case, stearic acid ethylene glycol monoester with a $8 \mathrm{wt} \%$ ratio was used as a plasticizer. Slightly lower tensile strength and Young's modulus values were obtained with $10 \mathrm{wt} \%$ ratio of this plasticizer (C 14), respectively $34.2 \mathrm{MPa}$ and $2853 \mathrm{MPa}$. A similar result was obtained for the sample $\mathrm{C} 16$ (palmitic acid ethylene glycol monoester) with a $8 \mathrm{wt} \%$ ratio: a tensile strength value of $34.4 \mathrm{MPa}$ and a Young's modulus of $2682 \mathrm{MPa}$. Sample C 10 with the addition of oleic acid ethylene glycol monoester was characterized by slightly lower values of both tested parameters. Among ethylene glycol esters it can be noticed that only in the case of the lauric acid ethylene glycol monoester (C 19), e.g. the acid with the shortest hydrocarbon chain among those used in the research, Young's modulus value was significantly reduced to $1901 \mathrm{MPa}$.

However even lower tensile strength and Young's modulus values were obtained when oleic and stearic acid methyl esters were used as plasticizers. The lowest tensile strength 
Table 8 Results of the mechanical testing

\begin{tabular}{|c|c|c|c|c|c|c|c|c|c|c|c|c|c|c|c|c|}
\hline \multirow[t]{3}{*}{ Compound name } & \multicolumn{4}{|c|}{$\begin{array}{l}\text { Charpy noched } \\
\left(\mathrm{kJ} / \mathrm{m}^{2}\right)\end{array}$} & \multicolumn{4}{|c|}{$\begin{array}{l}\text { Tensile strength } \\
\text { (MPa) }\end{array}$} & \multicolumn{4}{|c|}{$\begin{array}{l}\text { Young's modulus } \\
(\mathrm{MPa})\end{array}$} & \multicolumn{4}{|c|}{$\begin{array}{l}\text { Elongation at break } \\
(\%)\end{array}$} \\
\hline & \multicolumn{2}{|c|}{1 day } & \multicolumn{2}{|c|}{1 month } & \multicolumn{2}{|l|}{1 day } & \multicolumn{2}{|c|}{1 month } & \multicolumn{2}{|l|}{1 day } & \multicolumn{2}{|c|}{1 month } & \multicolumn{2}{|c|}{1 day } & \multicolumn{2}{|c|}{1 month } \\
\hline & $\mathrm{x}$ & s & $\mathrm{x}$ & $\mathrm{s}$ & $\mathrm{x}$ & $\mathrm{s}$ & $\mathrm{x}$ & $\mathrm{s}$ & $\mathrm{x}$ & $\mathrm{s}$ & $\mathrm{x}$ & $\mathrm{s}$ & $\mathrm{X}$ & $\mathrm{S}$ & $\mathrm{x}$ & $\mathrm{S}$ \\
\hline PHB-V & 1.4 & 0.1 & 1.5 & 0.5 & 42.0 & 0.3 & 44.7 & 0.7 & 3283 & 69 & 3977 & 152 & 3.8 & 0.1 & 3.3 & 0.4 \\
\hline C 1 & 3.7 & 0.6 & 2.6 & 0.1 & 32.9 & 0.2 & 34.3 & 0.3 & 2172 & 65 & 2490 & 78 & 6.8 & 0.3 & 5.8 & 0.5 \\
\hline C 2 & 4.0 & 0.2 & 3.6 & 0.4 & 28.9 & 0.7 & 30.1 & 0.5 & 1886 & 21 & 2199 & 66 & 5.9 & 0.8 & 4.9 & 0.3 \\
\hline C 7 & 4.0 & 0.5 & 3.6 & 0.1 & 32.8 & 0.8 & 34.3 & 0.7 & 2312 & 156 & 2583 & 158 & 6.4 & 1.1 & 5.9 & 0.8 \\
\hline C 8 & 3.4 & 0.4 & 3.2 & 0.6 & 30.4 & 0.8 & 31.4 & 1.3 & 2141 & 180 & 2300 & 91 & 6.2 & 1.2 & 5.3 & 1.0 \\
\hline C 10 & 2.9 & 0.3 & 3.2 & 0.4 & 32.4 & 0.2 & 34.7 & 0.2 & 2114 & 20 & 2502 & 176 & 6.7 & 0.1 & 5.8 & 0.3 \\
\hline C 13 & 1.8 & 0.2 & 2.0 & 0.1 & 36.9 & 0.5 & 37.6 & 1.1 & 3142 & 89 & 3548 & 175 & 4.5 & 0.3 & 3.2 & 0.9 \\
\hline C 14 & 2.2 & 0.2 & 2.1 & 0.1 & 34.2 & 0.9 & 35.7 & 0.5 & 2853 & 125 & 3210 & 71 & 4.6 & 0.7 & 4.1 & 0.1 \\
\hline C 16 & 2.3 & 0.6 & 2.1 & 0.1 & 34.6 & 0.2 & 36.3 & 0.4 & 2682 & 121 & 3112 & 119 & 5.3 & 0.6 & 4.5 & 0.5 \\
\hline C 17 & 2.6 & 0.6 & 2.4 & 0.5 & 32.8 & 1.0 & 34.8 & 1.0 & 2775 & 268 & 3016 & 137 & 4.7 & 1.0 & 4.7 & 0.9 \\
\hline C 19 & 4.1 & 0.3 & 4.0 & 0.4 & 31.3 & 0.8 & 33.8 & 0.3 & 1901 & 26 & 2381 & 122 & 6.4 & 1.1 & 5.9 & 0.4 \\
\hline
\end{tabular}

$x$ average value, $s$ standard deviation and Young's modulus values was characterized for sample C 2 with a value of $28.9 \mathrm{MPa}$ and $1886 \mathrm{MPa}$ respectively. In this case oleic acid methyl ester was used as plasticizer with $10 \mathrm{wt} \%$ ratio.

Comparing the results of mechanical tests obtained for PHB-V compounds containing fatty acid esters as plasticizers it can be assumed that both the presence of the unsaturated bond in the structure of the plasticizer and the shortening hydrocarbon chain length in the structure of the plasticizer affect the reduction tensile strength and Young's modulus values. On the other hand, the presence of free hydroxyl groups in the structure of the plasticizer molecule clearly contributes to a smaller reduction in tensile strength and Young's modulus values.

During ageing of PHB plasticized by poly(ethylene glycol)s Farris et al. [27] observed that Young's modulus and tensile strength increased, as a result the occurrence of material embrittlementthe. De Koning et al. [28] obtained similar results, they observed a significant decrease in ductility of PHB after 2 weeks storage time. According to Srubar et al. [29] as time passes the amorphous regions undergo glassy aging in the rigid amorphous fraction. Excess free volume is eliminated, in consequence stiffening of the amorphous material occurred. Therefore from the point of view of the practical application of the prepared PHB-V compounds, it is important to verify their mechanical properties after a certain storage time in room temperature to investigate the aging effect.

The results show that for all tested PHB-V compounds Young's modulus and tensile strength increased as function of time, what is related with the occurrence of material embrittlement. However the analysis of the aging effect of the produced PHB-V compounds showed that the change in the properties is much lower than expected as the difference in the values measured 1 day and 1 month after tensile bar production is quite low. Beyond the decrease in ductility (impact properties) and elongation at break is comparable low. For example, for the PHB-V compounds C 2, C 7 and C 19 with the highest Charpy notched value: 4.0, 4.0 and $4.1 \mathrm{~kJ} / \mathrm{m}^{2}$ after 1 month aging the Charpy notched value were respectively $3.6,3.6$, and $4.0 \mathrm{~kJ} / \mathrm{m}^{2}$. In contrary to our expectations the two PHB-V compounds C 10 (oleic acid ethylene glycol monoester as plasticizer) and C 13 (stearic acid ethylene glycol monoester as plasticizer show a slightly increase in the Charpy impact properties from 2.9 to $3.2 \mathrm{~kJ} /$ $\mathrm{m}^{2}$ and respectively from 1.8 to $2.0 \mathrm{~kJ} / \mathrm{m}^{2}$. Also the tensile strength values of the samples show only a marginal increase in the level of $5 \%$ while the elongation at break properties slightly decrease in the range of 0-29\%. A summary of the mechanical test results is given in Table 8 .

\section{Conclusions}

Plasticizer structure significantly affect the mechanical properties of the PHB-V compounds. Their molecules can penetrate between PHB-V macromolecules and thus increasing the "free volume" in polymer structure. This leads to an increased mobility of the polymer chains and to a decrease in rigidity. Generally, the used plasticizers lead to a slight decrease in the crystallization temperature while the crystallization enthalpy and thus degree of crystallization is not noticeable effected compared to value of the reference sample. Further the implementation of plasticizers in PHB-V matrix increases the impact properties and long term stability properties of the produced samples.

The best impact properties can be obtained with sample C 2, C 7 and sample C 19, to which as plasticizers were used 
respectively oleic acid methyl ester, palmitic acid methyl ester and lauric acid ethylene glycol monoester. For all these samples the impact strength increased from $1.4 \mathrm{~kJ} / \mathrm{m}^{2}$ (neat polymer) to a value of $4.0-4.1 \mathrm{~kJ} / \mathrm{m}^{2}$. Further the strength properties decrease, however remain on a level which is still adequate to be used in technical applications. It can be assumed that low molecular weight and linear molecules of lauric acid and palmitic acid esters and higher molecular weight molecules of oleic acid methyl ester with bent structure of hydrocarbon chains, effectively reduce the contact between the polymer chains. It results in a more flexible material with an increased ability to deformation without cracks.

Besides the improvement in the impact properties the plasticizers also positively affect the aging behavior of PHB-V and particularly limit the increase in brittleness over time which is seen as major drawback of these materials. Again sample C 2 and C19 shows stable impact strength properties with a slight increase in stiffness and strength properties.

Based on experimental results lauric acid ethylene glycol monoester and oleic acid methyl ester seem the most suitable for plasticizing PHB-V, since both show a good miscibility with PHB-V, good plasticizing properties and the mechanical properties of their PHB-V compounds are low affected by the ageing, and appear stable after 1 month from production. Summarizing in order to achieve the expected plasticizer and PHB-V compatibility and in the next step the plasticizer effectiveness, it is necessary to adapt three elements of plasticizer characteristic: spatial structure, molecular weight and the content of functional groups.

Acknowledgements This work was carried out within the project "Development of tailor-made PHB composites for technical applications", acronym PHB2MARKET realized within ERA-IB2 Programme, 7th Call, with financial support from the "National Centre for Research and Development" (Poland) and "Federal Ministry of Education and Research" (Germany).

Data Availability The datasets generated during and/or analysed during the current study are available from the corresponding author on reasonable request.

Open Access This article is licensed under a Creative Commons Attribution 4.0 International License, which permits use, sharing, adaptation, distribution and reproduction in any medium or format, as long as you give appropriate credit to the original author(s) and the source, provide a link to the Creative Commons licence, and indicate if changes were made. The images or other third party material in this article are included in the article's Creative Commons licence, unless indicated otherwise in a credit line to the material. If material is not included in the article's Creative Commons licence and your intended use is not permitted by statutory regulation or exceeds the permitted use, you will need to obtain permission directly from the copyright holder. To view a copy of this licence, visit http://creativecommons.org/licenses/by/4.0/.

\section{References}

1. Chen G-Q (2010) Plastics from bacteria, natural functions and applications. Springer, Berlin, Heidelberg

2. Bugnicourt E, Cinelli P, Lazzeri A, Alvarez V (2014) Polyhydroxyalkanoate (PHA): review of synthesis, characteristics, processing and potential applications in packaging. Polym Lett 8(11):791

3. Baltieri RC, Mei LHI, Bartoli J (2003) Study of the influence of plasticizers on the thermal and mechanical properties of poly(3hydroxybutyrate) compounds. Macromol Symp 197:33

4. Martino L, Berthet M-A, Angellier-Coussy H, Gontard N (2015) Understanding external plasticization of melt extruded PHB-Vwheat straw fibers biodegradable composites for food packaging. J Appl Polym Sci 132(10):41611

5. Sudesh K, Abe H, Doi Y (2000) Synthesis, structure and properties of polyhydroxyalkanoates: biological polyesters. Prog Polym Sci 25(10):1503

6. Wang L, Zhu W, Wang X, Chen X, Chen G-Q, Xu K (2008) Processability modifications of poly(3-hydroxybutyrate) by plasticizing, blending, and stabilizing. J Appl Polym Sci 107:166

7. Requena R, Jiménez A, Vargas M, Chiralt A (2016) Effect of plasticizers on thermal and physical properties of compressionmoulded poly[(3-hydroxybutyrate)-co-(3-hydroxyvalerate)] films. Polym Test 56:45

8. Altaee N, El-Hiti G, Fahdil A, Sudesh K, Yousi E (2016) Biodegradation of different formulations of polyhydroxybutyrate films in soil. SpringerPlus 5:762

9. Rosa DS, Calil MR, Fassina C, Santos EE (2001) The effect of UV-B irradiation on the biodegradability of poly-hydroxybutyrate (PHB) and poly-"-caprolactone (PCL). J Polym Environ 98:1439

10. Numata K, Abe H, Iwata T (2009) Biodegradability of poly(hydroxyalkanoate) materials. Materials 2:1104

11. Angelini S, Cerruti P, Immirzi B, Scarinzi G, Malinconico M (2016) Acid-insoluble lignin and holocellulose from a lignocellulosic biowaste: bio-fillers in poly(3-hydroxybutyrate). Eur Polym J 76:63

12. Zhu Ch, Nomura ChT, Perrotta JA, Stipanovic AJ, Nakas JP (2012) The effect of nucleating agents on physical properties of poly-3-hydroxybutyrate (PHB) and poly-3-hydroxybutyrateco-3-hydroxyvalerate (PHB-co-HV) produced by Burkholderia cepacia ATCC 17759. Polym Test 31:579

13. Seoane IT, Manfredi LB, Cyras VP (2018) Effect of two different plasticizers on the properties of poly(3-hydroxybutyrate) binary and ternary blends. J Appl Polym Sci 135(12):46016

14. Ceccorulli G, Pizzoli M, Scandola M (1992) Plasticization of bacterial poly(3-hydroxybutyrate). Macromolecules 25(12):3304

15. Slongo MD, Brandolt SDF, Daitx TS, Mauler RS, Giovanela M, Crespo JS et al (2018) Comparison of the effect of plasticizers on PHB-V - and organoclay - based biodegradable polymer nanocomposites. J Polym Environ 26(6):2290

16. Janigova I, Lacik I, Chodak I (2002) Thermal degradation of plasticized poly(3-hydroxybutyrate) investigated by DSC. Polym Degrad Stab 77:35

17. Abe H, Doi Y, Satkowski MM, Noda I (1994) Morphology and enzymatic degradation of poly $[(R)-3$-hydroxybutyrate] plasticized with acylglycerols. Stud Polym Sci 12:591

18. Erceg M, Kovacic T, Klaric I (2005) Thermal degradation of poly(3-hydroxybutyrate) plasticized with acetyl tributyl citrate. Polym Degrad Stab 90:313

19. Correa MCS, Branciforti MC, Pollet E, Agnelli JAM, Nascente PAP, Averous L (2012) Elaboration and characterization of nano-biocomposites based on plasticized 
poly(hydroxybutyrate-co-hydroxyvalerate) with organo-modified montmorillonite. J Polym Environ 20:283

20. Choi JS, Park WH (2004) Effect of biodegradable plasticizers on thermal and mechanical properties of poly(3-hydroxybutyrate). Polym Test 23(4):455

21. Yoshiea N, Nakasato K, Fujiwara M, Kasuya K, Abe H, Doi Y, Inoue Y (2000) Effect of low molecular weight additives on enzymatic degradation of poly(3-hydroxybutyrate). Polymer 41:3227

22. Bibers I, Tupureina V, Dzene A, Kainins M (1999) Improvement of the deformative characteristics of poly- $\beta$-hydroxybutyrate by plasticization. Mech Compos Mater 35(4):357

23. Savenkova L, Gercberga Z, Nikolaeva V, Dzene A, Bibers I, Kalnin M (2000) Mechanical properties and biodegradation characteristics of PHB-based films. Process Biochem 35:573

24. Jost V, Langowski H-C (2015) Effect of different plasticisers on the mechanical and barrier properties of extruded cast PHB-V films. Eur Polym J 68:302

25. Srithep Y, Ellingham T, Peng J, Sabo R, Clemons C, Turng L-S et al (2013) Melt compounding of poly (3-hydroxybutyrate-co3-hydroxyvalerate)/nano fibrillated cellulose nanocomposites. Polym Degrad Stab 98(8):1439
26. Grassie N, Murray EJ, Holmes PA (1984) The thermal degradation of poly(-(d)- $\beta$-hydroxybutyric acid): Part 2 - changes in molecular weight. Polym Degrad Stab 6(2):95

27. Farris G, Cinelli P, Anguillesi I, Salvadori S, Coltelli M-B, Lazzeri A (2014) Effect of ageing time on mechanical properties of plasticized poly(hydroxybutyrate) (PHB). AIP Conf Proc 1599(1):294

28. de Koning GJM, Lemstra PJ (1993) Crystallization phenomena in bacterial poly[(R)-3-hydroxybutyrate]: 2. embrittlement and rejuvenation. Polymer 34(19):4089

29. Srubar WV, Wright ZC, Tsui A, Michel AT, Billington SL, Frank CW (2012) Characterizing the effects of ambient aging on the mechanical and physical properties of two commercially available bacterial thermoplastics. Polym Degrad Stab 97(10):1922

Publisher's Note Springer Nature remains neutral with regard to jurisdictional claims in published maps and institutional affiliations. 